\title{
Laparoscopic Liver Resection in the Netherlands: How Far Are We?
}

\author{
Jan H.M.B. Stoot ${ }^{a, b}$ Edgar M. Wong-Lun-Hing ${ }^{a}$ Ione Limantoro ${ }^{a}$ Ruben Visschers ${ }^{a, b}$ \\ Olivier R. Busch ${ }^{c}$ Richard Van Hillegersberg ${ }^{d}$ Koert M. De Jong ${ }^{e}$ Arjen M. Rijken ${ }^{f}$ Geert Kazemier $^{g}$ \\ Steven W.M. Olde Damink ${ }^{a}$ h Toine M. Lodewick ${ }^{a}$ Marc H.A. Bemelmans ${ }^{a}$ Ronald M. van Dam ${ }^{a}$ \\ Cornelis H.C. Dejong ${ }^{a}$ on behalf of the Dutch Liver Collaborative Group \\ ${ }^{a}$ Department of Surgery, Maastricht University Medical Centre (MUMC), and Nutrim, School for Nutrition, Toxicology \\ and Metabolism, Maastricht, ${ }^{b}$ Department of Surgery, Orbis Medical Centre (OMC), Sittard, ' Department of Surgery, \\ Academic Medical Centre (AMC), Amsterdam, ${ }^{d}$ Department of Surgery, University Medical Centre Utrecht (UMCU), \\ Utrecht, e'Department of Surgery, University Medical Centre Groningen (UMCG), Groningen, fDepartment of Surgery, \\ Amphia Hospital, Breda, and 9Department of Surgery, Erasmus Medical Centre, Rotterdam, The Netherlands; \\ h Department of Surgery, University College Hospital London, London, UK
}

\section{Key Words}

Laparoscopic liver surgery · Systematic review ·

Complications $\cdot$ Hospital length of stay $\cdot$ ASA classification $\cdot$

Liver tumor

\begin{abstract}
Background: The objective of this study was to provide a systematic review on the introduction of laparoscopic liver surgery in the Netherlands, to investigate the initial experience with laparoscopic liver resections and to report on the current status of laparoscopic liver surgery in the Netherlands. Methods: A systematic literature search of laparoscopic liver resections in the Netherlands was conducted using PubMed/MEDLINE. Analysis of initial experience with laparoscopic liver surgery was performed by case-control comparison of patients undergoing laparoscopic left lateral sectionectomy matched with patients undergoing the open procedure in the Netherlands between the years 2000 and 2008. Furthermore, a nationwide survey was conducted in 2011 on the current status of laparoscopic liver surgery. $\boldsymbol{R} \boldsymbol{e}$ sults: The systematic review revealed only 6 Dutch reports on actual laparoscopic liver surgery. Matched case-control
\end{abstract}

comparison showed significant differences in the length of hospital stay, blood loss and operation time. Complications did not differ significantly between the two groups (26 vs. 21\%). The 2011 survey showed that 21 centers in the Netherlands performed formal liver resections and that 49 (5\% of total) laparoscopic liver resections were performed in 2010. Conclusion: The systematic review revealed that very few laparoscopic liver resections were performed in the Netherlands in the previous millennium. The matched case-control comparison of laparoscopic and open left lateral resection showed a reduction in hospital length of stay with comparable morbidity. The laparoscopic technique has been slowly adopted in the Netherlands, but its popularity seems to increase in recent years.

Copyright $\odot 2012$ S. Karger AG, Basel

Preliminary results of this study were presented at the Congress of the European Hepato-Pancreatico Biliary Association in Athens, Greece, in 2009, the 17th International Congress of the European Association for Endoscopic Surgery in Prague, Czech Republic, in 2009, the Annual Congress of the Association of Surgeons of Great Britain and Ireland in Glasgow, UK, in 2009, and the European Postgraduate Gastro-Surgical School during 'One day on techniques of liver resection' in Amsterdam, The Netherlands, in 2011.

\section{KARGER}

Fax +41613061234 E-Mail karger@karger.ch www.karger.com

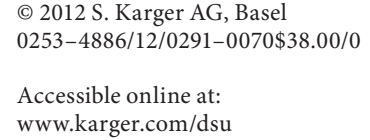

J.H.M.B.Stoot

Department of Surgery, Maastricht University Medical Centre

P. Debyelaan 25, PO Box 5800

NL-6202 AZ Maastricht (The Netherlands)

Tel. +31 88459 7777, E-Mail jan@ stoot.com 


\section{Introduction}

In the past two decades, the popularity of laparoscopic surgery has grown. The introduction of laparoscopic cholecystectomy $[1,2]$ has led to an increasing number of indications for this technique, and has encouraged surgeons to develop a laparoscopic approach for many procedures including liver resections [3]. Laparoscopic liver resections are technically demanding and thought to be time-consuming $[4,5]$ but may have several important benefits for the patient compared to open liver surgery [6-8]. The putative advantages of this minimally invasive procedure include reduced blood loss [6,7], less postoperative pain $[5,9,10]$, earlier recovery and shorter postoperative hospital stay [5, 7-12], and improved cosmetic aspects $[9,12]$. Reoperations are reported to be easier due to reduced adhesions [9-12]. Also, open-close procedures with large incisions can be avoided when peritoneal metastases are detected at laparoscopy.

In the Netherlands, the gold standard for liver resection for liver tumors still is the open approach. There is no best level of evidence (level 1) to underpin the supposed major benefits of the laparoscopic approach, but the latter has been proven to be feasible and safe in many international expert centers. A recent consensus statement on laparoscopic liver resections states that resection of segments 2 and 3 by the laparoscopic approach should be the standard if experience is available [13]. In addition, the largest reviews hitherto conducted concluded that laparoscopic liver surgery is feasible and safe in minor as well as major liver resections when performed in experienced centers $[14,15]$. However, randomized trials comparing the open and laparoscopic technique for liver resections are still lacking.

The purpose of our study was (1) to provide a historical overview on the introduction and initial experience of laparoscopic liver surgery in the Netherlands against the background of the latest international developments, (2) to report on the present state of laparoscopic liver surgery in the Netherlands, and (3) to provide insight into current and future developments of the minimally invasive liver resection technique within the Netherlands. To this purpose, a systematic review of all Dutch papers reporting on laparoscopic liver surgery was done and key leaders were informally approached. A matched case-control comparison was carried out of laparoscopic versus open liver resections in the Netherlands performed from 2000 to 2008. Finally, recent advances made in the Dutch surgical field of laparoscopic hepatectomies were investigated by means of a nationwide survey.

Laparoscopic Liver Resection in the

Netherlands

\section{Methods}

Systematic Review of Laparoscopic Liver Surgery in the

Netherlands - Past Experience

An online search was performed in PubMed/Embase databases for reports of Dutch groups on their experience with laparoscopic liver surgery in humans. Databases were searched from the earliest data available until 1 June 2011 on a combination of the following search keywords: 'laparoscopy', 'liver surgery', 'hepatic surgery', 'hepatic resection', 'hepatectomy', 'minimally invasive liver surgery', 'minimally invasive hepatic resection', 'Dutch', 'The Netherlands'. Biliary tumors were excluded. Titles and abstracts were screened (E.W.L.H.) and relevant articles selected. The full text of eligible papers was attempted to be retrieved to provide a historical overview. The reference lists of retrieved articles were reviewed for additional potentially relevant studies. To complete the historical picture, key leaders in gastrointestinal surgery were informally queried about their past experience and recollection of the evolution of laparoscopic liver surgery in the Netherlands.

Initial Experience with Laparoscopic Liver Resections and Case-Control Comparison - Present State

Patients

All major liver centers in the Netherlands were contacted during 2008 by phone and/or e-mail and asked to participate in this study. Of the fourteen major HPB centers in the Netherlands, only seven had performed laparoscopic liver resections. Six of these centers agreed to collaborate. Data were obtained retrospectively from six separate prospectively collected databases used in these six HBP units and were pooled for further analysis. All patients who underwent laparoscopic left lateral sectionectomies of the liver in the six centers between 2000 and 2008 were included in this multicenter study. The laparoscopic group of patients was compared in a case-matched comparison approach with a group of patients undergoing the same type of liver resection as an open procedure in that era in the 6 participating centers in a proportion of 1:3. This approach and the choice to only include left lateral sectionectomies were felt to be justified to eliminate bias as much as possible and increase the externalvalidity of the conclusions. The investigators (J.H.M.B.S. and I.L.) were unaware of the primary outcome or secondary outcomes during the selection process. Patients undergoing left lateral resections in combination with colonic resections were excluded.

In each unit, patients were preoperatively discussed in a multidisciplinary meeting, after evaluation of liver function tests and radiologic liver workup including abdominal ultrasonography, CT, MRI and/or CT-PET scan. Patients with benign as well as malignant solid liver lesions were included in this study. Patients with cystic lesions of the liver were excluded. Laparoscopic liver resection was considered if the lesion was located in the left lateral segments (segment 2 and 3 according to Couinaud's classification). The choice to perform either a laparoscopic or open procedure was at the discretion of the attending surgeon in consent with the patient. Preoperative information consisted of medical history, preoperative diagnosis and American Society of Anesthesiologists (ASA) classification. 


\section{Surgical Procedures}

The open procedure was started with a $15-$ to $25-\mathrm{cm}$ incision according to the preference of the surgeon. During operation, the left liver was mobilized, and central venous pressure was maintained at 2-6 $\mathrm{mm} \mathrm{Hg}$. Transection of the liver was performed according to the preference of the surgeon: the Cavitron Ultrasonic Surgical Aspirator (CUSA ${ }^{\circledR}$; Valleylab, Boulder, Colo., USA) and argon beam coagulator (Bircher Ind., Ltd., Englewood, Colo., USA) with or without the use of Pringle's maneuver, Ultracision Harmonic ACE (Ethicon Endosurgery, Johnson \& Johnson, USA) or Ligasure (Covidien, USA). Only occasionally was the clampcrush technique used. Minor crossing vessels and biliary radicals were divided using polypropylene sutures or clips. The portal pedicles and hepatic veins were divided and ligated with a running polypropylene suture. In some procedures, vascular staplers such as e.g. Autosuture EndoGIA (Covidien) were used. After removal of the liver specimen, the raw surface of the liver remnant was subjected to argon beam coagulation and sealed with $\mathrm{Ta}$ choSil $^{\circledR}$ (Nycomed, Zurich, Switzerland) or Tissuecoll (Baxter, Vienna, Austria) if considered appropriate.

The laparoscopic procedure was performed as described in detail previously [16]. The patient was in the supine French position and abdominal access was achieved by transumbilical open insertion of a laparoscope. Pneumoperitoneum was kept at 10 $14 \mathrm{~mm} \mathrm{Hg}$; three or four additional $12-\mathrm{mm}$ trocars were added, and a $30^{\circ}$ laparoscope was used routinely. The central venous pressure was maintained at 2-6 $\mathrm{mm} \mathrm{Hg}$. Hepatic transection of parenchyma and minor crossing vessels and biliary radicals was mainly performed with harmonic scalpel (Ultracision, Ethicon Endosurgery, Johnson \& Johnson, USA) or the Ligasure (Covidien). The segmental portal pedicles and left hepatic vein were stapled using a vascular stapler (EndoGIA Autosuture, Covidien). Resected specimens were placed in a plastic bag (Endocatch Autosuture, Covidien) and removed through a separate incision.

\section{Parameters and Outcome}

Peri- and postoperative parameters included type of resection, operation time, blood loss, need for transfusion, conversion of laparoscopic to open procedure, postoperative complications, postoperative length of hospital stay and pathologic assessment of the resected liver segment. Blood loss was measured by the suction device and the weight of the gauzes and recorded in operation notes and/or anesthesia reports. In case of discrepancy, the highest amount was used. Data on surgical technique consisted of information about type of incisions, type of liver resection, method of liver transection, hemorrhage control, use of hemostatic agents, Pringle maneuver, and method of extraction of surgical specimen. In one center (Maastricht University Medical Centre, MUMC), a multimodal perioperative enhanced recovery program $\left(\right.$ ERAS $\left.^{\circledR}\right)$ was followed for all patients undergoing liver surgery $[16,17]$. This was also recorded as a parameter. Criteria for discharge in the ERAS setting were described previously [16, 17]. Discharge in the traditional setting was at the discretion of the attending surgeon.

Primary outcome of the study was hospital length of stay. Secondary outcome measures comprised complications (including mortality and conversion rates), duration of operation and blood loss. Postoperative complications were defined according to the international grading system of Dindo et al. [18].
Current Status of Laparoscopic Liver Surgery -

Future Developments

To get an indication of the volumes currently being operated on in Dutch hospitals, and to see whether they had increased in the years following the introduction of the minimally invasive technique, we approached all Dutch hospitals that indicated to perform liver surgery in January 2011 by e-mail. This contained three questions surveying on (1) whether the hospital performed formal liver resections (not only deroofing of cysts), (2) how many open/laparoscopic major or minor hepatic resections were performed in 2010, and (3) whether the provided data were real or estimated numbers. Centers that did not reply on the request to complete the survey were approached by phone in February 2011.

\section{Statistical Analysis}

Data were analyzed by J.S., I.L. and R.V; if necessary, an independent statistician was consulted. Continuous variables are expressed as mean ( \pm standard error of the mean). Data were analyzed according to the intention to treat principle. Univariable analysis was performed using Pearson's $\chi^{2}$ test (or Fisher's exact test where appropriate) to investigate differences between open and laparoscopic procedures regarding sex, indication, pathology, resection margins, ERAS, use of Pringle maneuver, method of liver transection, hemorrhage control and hemostatic agents, use of staplers and complications. The Mann-Whitney U test was used for univariable analysis to investigate differences between open and laparoscopic surgery regarding age, ASA classification, tumor diameter, type of incision, complication classification, hospital length of stay (days), duration of operation ( $\mathrm{min}$ ), blood loss $(\mathrm{ml})$ and number of transfusions. The relation between patient characteristics and operative strategy and length of hospital stay was analyzed with univariable linear regression analysis. All independent variables with a two-tailed p value below 0.200 were included into a multivariable linear regression model using backward analysis to assess which parameters were significantly and independently related to length of hospital stay. Also, the group effect of open versus laparoscopic resections on postoperative hemoglobin was analyzed using multivariable linear regression analysis correcting for preoperative hemoglobin levels. A p value below 0.05 was considered to indicate statistical significance. Statistical analyses were performed using SPSS software (version 15; SPSS Inc., USA).

\section{Results}

\section{Systematic Review of Laparoscopic Liver Surgery in the Netherlands - Past Experience}

A total of 91 abstracts were retrieved that met the search terms, and after review 19 abstracts remained eligible. Of these 19 articles, 6 reported on actual laparoscopic liver surgery, 12 described the use of laparoscopy and/or laparoscopic ultrasound for staging in patients with hepatic tumors, and one article provided a literature review on liver resection and laparoscopy (fig. 1). The informal interviews and articles eligible for review revealed that the first two laparoscopic liver resections were per- 
formed in Amsterdam in 1995 by the group of Cuesta et al. [19]. In the following years, only one article from the same group was published reporting on a series of laparoscopically operated patients $(n=10)$. Seven underwent a minor laparoscopic resection and three underwent fenestration of hepatic cysts [20]. After these initial reports on minimally invasive liver surgery, three articles were published with regard to laparoscopic treatment of polycystic liver disease [21-23]. Later series of 26 laparoscopic liver resections provided evidence that this procedure could be performed safely in the Netherlands [16].

\section{Initial Experience with Laparoscopic Liver Resections} and Case-Control Comparison - Present State

\section{Patient's Characteristics}

Between 2000 and 2008, the laparoscopic approach for hepatic left lateral sectionectomy was performed in 30 patients in 6 centers in the Netherlands (mean age $50 \pm$ 3 years) and completed laparoscopically in 27 patients. Five of the laparoscopic liver resections were performed hand-assisted. In the open group, 90 patients were matched for the same type of resection (mean age $52 \pm$ 2 years). Demographic data of both groups are reported in table 1 . There were no significant differences in age, ASA classification, indication, resection margins and tumor size.

\section{Surgical Procedures and Parameters}

The Pringle maneuver was only used during open surgery (table 2). The method of liver transection in the open group was different from the approach in the laparoscopic group. Mostly, the CUSA and/or argon beam was used in the open group for liver transection.

\section{Outcome Parameters}

Mean hospital length of stay was 6.0 ( \pm 0.4$)$ days in the laparoscopic group versus 8.1 ( \pm 0.4 ) days in the open group $(\mathrm{p}<0.001)$. Complication rates did not differ significantly between the laparoscopic and the open group (26 vs. $21 \%$ ), neither did they differ significantly when complications were graded according to severity intervention score. Three laparoscopic procedures (10\%) were converted to an open procedure (table 3). Reasons for conversion were hemorrhage, an additional lesion in segment IV or the close relation to the left hepatic vein. There were no deaths in the laparoscopic group. In the open group, one of the 90 patients (1.1\%) died due to multiple organ failure after sepsis.

There was significantly less blood loss in the laparoscopic group compared to the open group $(\mathrm{p}<0.001$; ta-

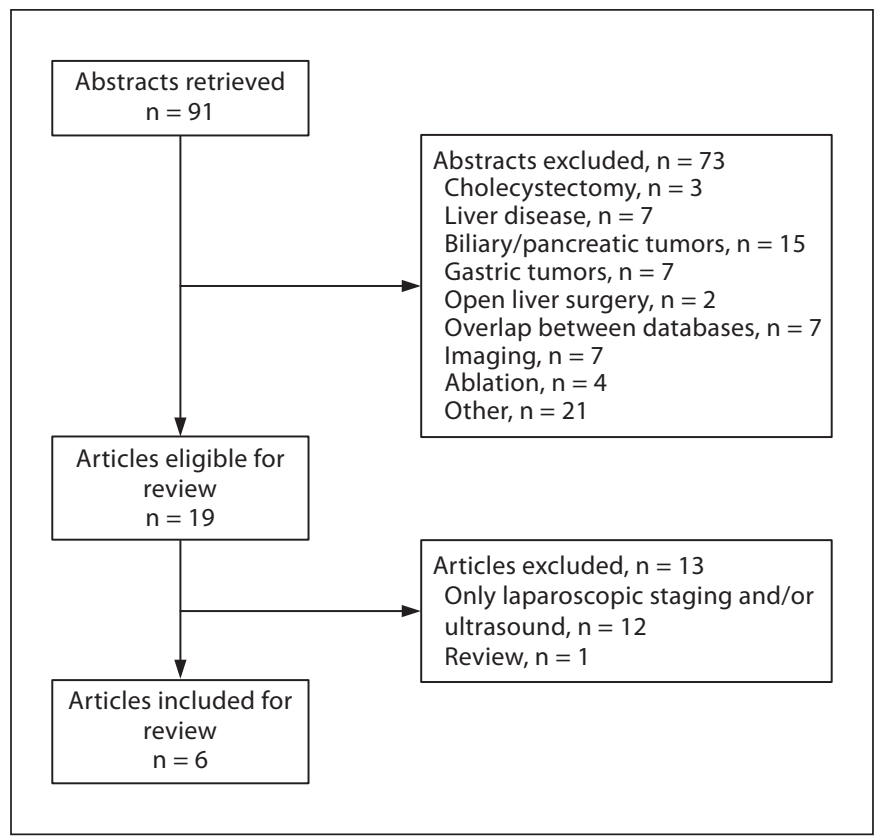

Fig. 1. Selection of studies eligible for review.

Table 1. Clinical and pathological features of the control study

\begin{tabular}{lcll}
\hline & $\begin{array}{c}\text { Laparoscopic } \\
\text { group }(\mathrm{n}=30)\end{array}$ & $\begin{array}{l}\text { Open group } \\
(\mathrm{n}=90)\end{array}$ & $\begin{array}{l}\mathrm{p} \\
\text { value }\end{array}$ \\
\hline Males/females $^{\mathrm{a}}$ & $5 / 25$ & $35 / 55$ & 0.043 \\
Age, years $^{\mathrm{b}}$ & $50(3)$ & $52(2)$ & 0.584 \\
ASA 1 & 10 & 18 & 0.625 \\
ASA 2 & 16 & 38 & \\
ASA 3 & 2 & 16 & \\
ASA 4 & 0 & 1 & \\
Indication (malignant/benign) & & \\
Tumor size, cm & $11 / 19$ & $39 / 51$ & 0.091 \\
Pathology (malignant/benign) & $4.8 \pm 0.5$ & $5.3 \pm 0.4$ & 0.673 \\
Resection margins (R0/R1/R2) & $7 / 22$ & $48 / 42$ & 0.007 \\
ERAS (yes/no) $^{\mathrm{a}}$ & $19 / 1 / 1$ & $64 / 8 / 2$ & 0.597 \\
& $11 / 19$ & $8 / 92$ & 0.001 \\
\hline
\end{tabular}

Values for tumor size are expressed as mean \pm standard error of mean.

${ }^{a}$ Pearson's $\chi^{2}$ test (or Fisher exact test where appropriate).

${ }^{b}$ Mann-Whitney U test.

${ }^{\mathrm{c}}$ Results do not add up to total values as a result of missing data.

${ }^{\mathrm{d}}$ In the laparoscopic group, two (R1 and R2) resection margins were positive, both in patients with benign disease (adenoma and hemangioma, respectively). In the open control group the R2 resections were suspected to be benign lesions preoperatively. However, one of these $\mathrm{R} 2$ resections proved to be malignant (hepatocellular carcinoma). Of the $\mathrm{R} 1$ resection margins, $3 / 8$ were malignant tumors. 
Table 2. Operative details on transection and hemostasis techniques and use of devices

\begin{tabular}{|c|c|c|}
\hline & $\begin{array}{l}\text { Laparoscopic } \\
\text { group }(\mathrm{n}=30)\end{array}$ & $\begin{array}{l}\text { Open group } \\
(\mathrm{n}=90)\end{array}$ \\
\hline Use of Pringle maneuver & $1(3)^{\mathrm{a}}$ & $20(22)$ \\
\hline \multicolumn{3}{|l|}{ Liver transection } \\
\hline CUSA \pm argon beam & $3(10)$ & $55(61)$ \\
\hline Ultracision & $21(70)$ & $4(4)$ \\
\hline Ligasure & $4(13)$ & $7(8)$ \\
\hline Hydrojet & & $2(2)$ \\
\hline CUSA + ligasure & & $8(9)$ \\
\hline Diathermia \pm endogia & & $4(4)$ \\
\hline Kelly clamp & & $1(1)$ \\
\hline Endogia & $2(7)$ & $4(4)$ \\
\hline \multicolumn{3}{|l|}{ Hemorrhage control $^{\mathrm{b}}$} \\
\hline Diathermia \pm argon beam & $6(20)$ & $4(4)$ \\
\hline Clips & $6(20)$ & $15(17)$ \\
\hline Prolene & $4(13)$ & $23(26)$ \\
\hline Clips and prolene & $1(3)$ & $39(43)$ \\
\hline Other: use of device & $9(30)$ & $3(3)$ \\
\hline Use of staplers (yes/no) ${ }^{\mathrm{b}}$ & $22 / 3^{a}$ & $19 / 68$ \\
\hline \multicolumn{3}{|l|}{ Hemostatic agents ${ }^{b}$} \\
\hline None & $19(63)$ & $39(43)$ \\
\hline Tachosyl & $4(13)$ & $17(19)$ \\
\hline Tissuecoll & $4(13)$ & $25(28)$ \\
\hline Surgicell & $1(3)$ & $1(1)$ \\
\hline Unknown & $1(3)$ & $7(8)$ \\
\hline
\end{tabular}

Figures in parentheses indicate percentages.

${ }^{a}$ Following conversion to open.

b Results do not add up to total values as a result of missing (non-reported) data.

Table 3. Primary and secondary outcomes (mean \pm SEM)

\begin{tabular}{lccr}
\hline & $\begin{array}{l}\text { Laparoscopic } \\
\text { group }(\mathrm{n}=30)\end{array}$ & $\begin{array}{l}\text { Open group } \\
(\mathrm{n}=90)\end{array}$ & $\begin{array}{l}\mathrm{p} \\
\text { value }\end{array}$ \\
\hline $\begin{array}{l}\text { Length of stay, days } \\
\text { Complications }^{\mathrm{b}}\end{array}$ & $6.0 \pm 0.4$ & $8.1 \pm 0.4$ & $<0.001$ \\
Complications $^{\mathrm{a}}$ & $5(17)$ & $19(21)$ & 0.620 \\
$\quad$ Grade 1 & $4(13)$ & $8(9)$ & 0.832 \\
$\quad$ Grade 2 & & $4(4)$ & \\
$\quad$ Grade 3a & $1(3)$ & $3(3)$ & \\
$\quad$ Grade 3b & & $2(2)$ & \\
$\quad$ Grade 4a & & $1(1)$ & \\
$\quad$ Grade 4b & & $1(1)$ & \\
$\quad$ Grade 5 & $3(10)$ & $3(3)$ & 0.589 \\
Conversions & $1(3)$ & $608 \pm 97$ & $<0.001$ \\
Reoperation & & & \\
Blood loss, ml & & $231 \pm 11$ & $<0.001$ \\
Operation time, min & $160 \pm 13$ & & \\
\hline
\end{tabular}

Figures in parentheses indicate percentages.

a Mann-Whitney U test.

b Pearson's $\chi^{2}$ test (or Fisher exact test where appropriate). ble 3). When corrected for preoperative hemoglobin level, multivariable analysis showed that open resection was significantly related to a decrease in postoperative hemoglobin levels compared to the laparoscopic group $(\mathrm{OR}=$ $-0.520, \mathrm{CI}-1.022$ to $-0.18, \mathrm{p}=0.043)$. None of the patients in the laparoscopic group needed a blood transfusion postoperatively in contrast to 22 blood transfusions in the open group. However, this difference was not significant. The mean duration of operation in the laparoscopic group was significantly shorter than in the open group $(\mathrm{p}<0.001$; table 3$)$.

Univariable regression analyses showed that several variables were related to differences in length of hospital stay (table 4). However, after multivariable regression analysis, only ASA classification $(\mathrm{OR}=1.598$, CI 0.738 $2.458, \mathrm{p}<0.001)$, complication grade $(\mathrm{OR}=1.680$, CI $1.124-2.235, \mathrm{p}<0.001)$ and ERAS $(\mathrm{OR}=-2.502, \mathrm{CI}-4.032$ to $-0.972, \mathrm{p}=0.002$ ) were independently and significantly related to length of hospital stay.

\section{Current Status of Laparoscopic Liver Surgery - \\ Future Developments}

The response rate to the nationwide survey was $81 \%$; 30 out of 37 approached hospitals responded. The seven non-responding centers were all district general hospital centers, except one university medical center. In total, 21 centers performed formal liver resections in 2010, the remaining 9 centers only performed deroofing procedures. The total number of hepatic resections performed in 2010 by the responding centers in the Netherlands was 966 . This total number of resections consisted of 444 major and 522 minor hepatectomies (fig. 2). During 2010, all Dutch hospitals together performed only 49 laparoscopic liver resections; $5 \%$ of all resections (fig. 3). All these minimally invasive surgical procedures were reported to be minor hepatic resections.

\section{Discussion}

This study provides a historical overview and reports on the initial experience and the current status of laparoscopic liver surgery in the Netherlands. A systematic review of the literature showed that the laparoscopic approach for hepatic resection was introduced in the Netherlands during the 1990s and that some, but limited experience has been gained. It is clear from the data and from additional information obtained by interviewing key leaders that only very few laparoscopic livers were performed in the previous millennium. 
Table 4. Univariable linear regression analysis of length of hospital stay

\begin{tabular}{|c|c|c|c|}
\hline Variable & $\begin{array}{l}\text { Odds } \\
\text { ratio }\end{array}$ & $95 \% \mathrm{CI}$ & $\begin{array}{l}\mathrm{p} \\
\text { value }\end{array}$ \\
\hline Age (years) & 0.040 & 0.001 to 0.079 & 0.047 \\
\hline Sex (male/female) & 1.374 & 0.022 to 2.276 & 0.046 \\
\hline Group (open/laparoscopic) & 2.012 & 0.571 to 3.452 & 0.007 \\
\hline Indication (malignant/benign) & 1.419 & 0.154 to 2.684 & 0.028 \\
\hline Pathology (malignant/benign) & 1.762 & 0.501 to 3.023 & 0.007 \\
\hline Tumor diameter $(\mathrm{cm})$ & 0.091 & -0.129 to 0.311 & 0.413 \\
\hline Complication $^{\mathrm{a}}$ & 1.559 & 1.025 to 2.093 & $<0.001$ \\
\hline Duration (min) & 0.008 & 0.001 to 0.015 & 0.020 \\
\hline ERAS (yes/no) & -1.392 & -3.136 to 0.352 & 0.117 \\
\hline Reoperation & 0.961 & -4.092 to 6.014 & 0.707 \\
\hline ASA $^{\mathrm{b}}$ & 1.840 & 0.849 to 2.830 & $<0.001$ \\
\hline Stapler (yes/no) & -1.637 & -3.014 to -0.261 & 0.020 \\
\hline Pringle (yes/no) & -0.762 & -2.130 to 0.606 & 0.272 \\
\hline \multicolumn{4}{|l|}{ Transection } \\
\hline CUSA & 1.523 & -1.803 to 4.848 & 0.366 \\
\hline Ultracision & 0.120 & -3.373 to 3.613 & 0.946 \\
\hline Ligasure & 0.309 & -3.536 to 4.155 & 0.874 \\
\hline Hydrojet & 1.400 & -4.565 to 7.365 & 0.643 \\
\hline CUSA and ligasure & 1.525 & -2.540 to 5.590 & 0.459 \\
\hline Other & -0.350 & -5.133 to 4.433 & 0.885 \\
\hline Kelly & 1.400 & -6.410 to 9.210 & 0.723 \\
\hline Endogia & 0.567 & -3.751 to 4.884 & 0.795 \\
\hline \multicolumn{4}{|l|}{ Hemorrhage control } \\
\hline Diathermia & -1.992 & -4.545 to 0.560 & 0.125 \\
\hline Clips & -0.942 & -3.320 to 1.435 & 0.433 \\
\hline Prolene & 1.197 & -0.606 to 3.000 & 0.191 \\
\hline Other & -1.276 & -3.653 to 1.102 & 0.289 \\
\hline \multicolumn{4}{|l|}{ Hemostatic agents } \\
\hline Tachosyl & -0.024 & -5.387 to 5.340 & 0.993 \\
\hline Tissuecol & 0.121 & -5.178 to 5.419 & 0.964 \\
\hline Surgicell & 3.000 & -4.248 to 10.248 & 0.414 \\
\hline None & -0.114 & -5.328 to 5.100 & 0.965 \\
\hline
\end{tabular}

${ }^{a}$ Complication according to Dindo et al. [18]; increase per unit increase severity.

${ }^{\mathrm{b}}$ Increase per unit increase severity.

Compared to countries that have traditionally always played a pioneering role in (laparoscopic) liver surgery, such as France, the Netherlands have fallen behind with regard to the implementation of the minimally invasive technique. Many surgeons considered an open partial liver resection to be major surgery associated with significant mortality and morbidity. Dutch surgeons remained reluctant to perform this type of surgery [24]. Illustrating this fact is that only $110-130$ partial liver resections (including benign tumors) were performed between 1984 and 1987. At the end of the 1980s and 1990s, several series

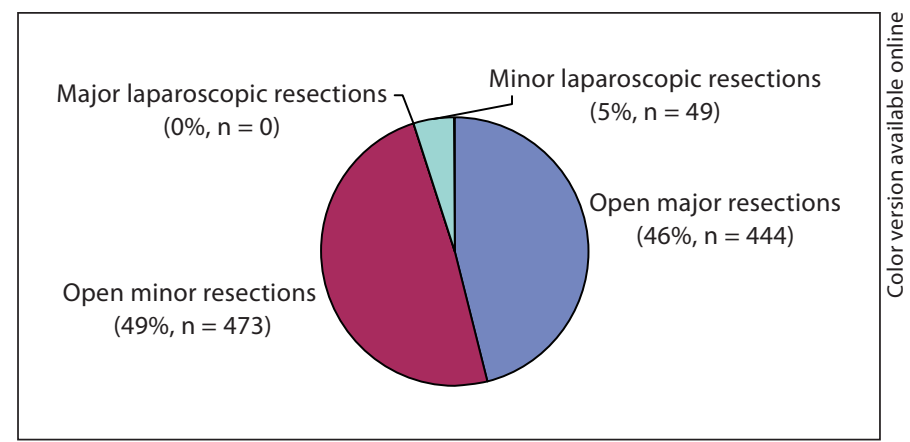

Fig. 2. Results of a nationwide survey of laparoscopic and open liver resections performed during 2010 in the Netherlands.

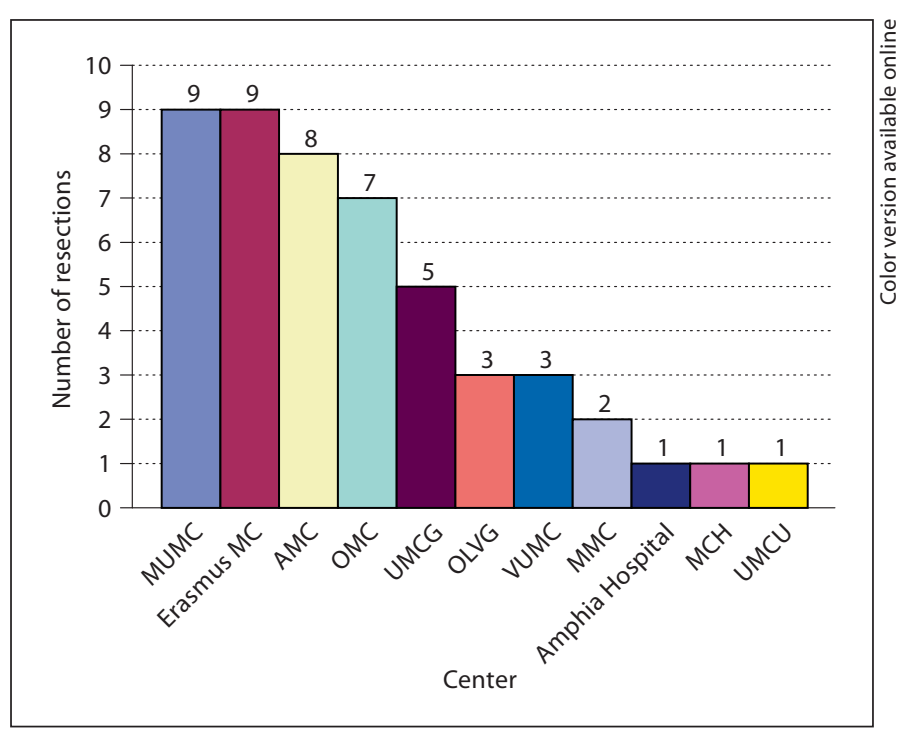

Fig. 3. Results of a nationwide survey of total laparoscopic (minor) liver resections performed during 2010 in the Netherlands per center. on the experience with open hepatic resection were published by different Dutch centers $[25,26]$.

The laparoscopic technique for liver resections was introduced in the Netherlands during the 1990s for diagnostic laparoscopies and liver biopsies. Later, the indications were extended to fenestration of liver cysts and anatomic liver resections [27-32]. The group of Cuesta et al. [19] was in 1995 the first to report two cases of limited laparoscopic liver surgery of segment II and IV in the Netherlands. A few years later, in 2001, a small retrospective series $(\mathrm{n}=10)$ was published that demonstrated en- 
couraging results concerning operative blood loss, postoperative complications and hospital length of stay after wedge and left lateral hepatectomy. Furthermore, they concluded that laparoscopic treatment should be considered in selected patients with benign and malignant lesions in the left lobe or frontal segments of the liver [20].

While the first limited laparoscopic liver resection in the Netherlands was performed in 1995, the first laparoscopic liver resection worldwide, a wedge resection, had already been performed by Gagner's group in 1992. Four years thereafter, Azagra's group reported the first anatomic liver resection [3]. In the following few years, the minimally invasive technique was further developed and adopted, resulting in the first laparoscopic left lateral sectionectomy for living liver donation [33] and the first reports on robotic liver surgery $[34,35]$. Initially, laparoscopic liver resection was challenging because of the difficulties concerning safe mobilization and exposure of this fragile and heavy organ $[3,36,37]$. Small, superficial and peripheral lesions in anterolateral segments were considered most amenable to laparoscopic liver resection. Surgeons with extensive experience in laparoscopy and hepatic surgery have performed laparoscopic major hepatic resections with satisfactory outcomes $[28,38,39]$.

Recent large reviews by Reddy et al. [15] and Nguyen et al. [14] show favorable outcomes after laparoscopic resection $[14,15]$. Patient benefits included less operative blood loss [6,7], less postoperative pain $[5,9,10]$ and narcotic requirement, improved cosmetic aspects $[9,12]$ and a shorter length of hospital stay [5,7-12] with postoperative morbidity and mortality comparable to open liver resection. In addition, the minimally invasive approach seems to be cost-effective $[40,41]$. Potential limitations and disadvantages of laparoscopic liver resection include a significant learning curve, potential bleeding which may be more difficult to control laparoscopically, inadequate assessment of the liver for additional lesions, and increased risk for gas embolism [15, 42]. Air embolism may occur when high-pressure pneumoperitoneum is used $[36,43]$. However, gas embolism is rare and usually well tolerated [5]. Other concerns have been raised about the potential dissemination of malignant cells during laparoscopic resection [44-46]. Some authors have suggested that tumor dissemination does not increase by laparoscopy [47-49], and recent reports regarding this subject show long-term survival rates comparable to open surgery [12, 37, 50, 51].

At present, after more than 10 years of experience and following advances in laparoscopic technology, the surgi- cal community has accepted that laparoscopic liver surgery is feasible and safe $[3,7,8,10,51-53]$. This is especially true for resection of left lateral segments and right anterior segments $[4,9,11,54]$. Some of the advantages reported in literature were also found in the present study. The present multicenter case-control study on laparoscopic left lateral sectionectomies in the Netherlands between 2000 and 2008 demonstrated that length of hospital stay for the laparoscopic approach for left lateral sectionectomies was reduced by 2 days. Furthermore, the laparoscopic approach resulted in faster procedures with reduced blood loss, no occurrence of gas embolisms and comparable morbidity. In a multivariable analysis, length of hospital stay appeared to be related to ASA classification, complications and ERAS.

Left lateral sectionectomy currently is the most common laparoscopic liver resection for solid tumors in the Netherlands. However, only a minority of left lateral sectionectomies were performed laparoscopically between 2000 and 2008. The laparoscopic approach has gained gradual acceptance by Dutch surgeons, but is still not a standard. A structured implementation may allow the Dutch surgical community to catch up with international developments. Recently, van Dam and Topal performed the first major laparoscopic liver resection in the Netherlands (anatomical right hemihepatectomy, Maastricht, 2011).

The question remains why the laparoscopic left sectionectomy in this study proved to be faster than the open counterpart. Differences in technique in transection of the liver parenchyma and the vascular and biliary structures may have added to a faster transection. Reduced blood loss, either caused by different transection devices or pneumoperitoneum, may reduce the need for prolene stitches and hemostatic clips, which can be time consuming. Lastly, there is no need to close the abdomen after the procedure.

The survey results demonstrate an increase in both totally laparoscopic and totally open liver resections performed in the Netherlands. Although more centers have adopted the laparoscopic approach in recent years, individual center volumes remain low. Only 5\% of all liver resections were performed laparoscopically, which is significantly less compared to other countries where average percentages of laparoscopic hepatic resections range between 20 and $80 \%$ [13]. If surgeons in the Netherlands aim to increase the portion of laparoscopic liver resections, liver surgery should be further centralized. Furthermore, a central training, proctoring and credentialing infrastructure should be developed to improve the 
quality of outcome parameters and to allow units to become (high-volume) expert centers.

The foundation of the Dutch Liver Collaborative Group in 2003 gave a new impulse to minimally invasive liver surgery, and is in concordance with recently made recommendations that national and international societies, as well as governing boards, should become involved in the goal of establishing training standards and credentialing [13]. Goals of this workgroup are to facilitate collaboration of medical centers in the field of hepatic surgery, initiate and facilitate research in liver surgery (especially multicenter trials), facilitate training, education and adoption and to establish a quality control and auditing system for Dutch liver surgery centers.

In conclusion, minimally invasive liver surgery is gradually being adopted in the Netherlands. The laparoscopic (left-sided) liver resection is a safe procedure, and it probably results in a shorter hospital length of stay with comparable morbidity. Laparoscopic liver resections appear to be faster. More importantly, ASA classification, complications and ERAS proved to be important prognostic variables for reduced length of hospital stay in Dutch hospitals. In the future, the Dutch Liver Collaborative Group should continue to play an important role in the further adoption and centralization of minimally invasive liver surgery. Conducting an RCT on laparoscopic liver resection may add to the body of evidence supporting broader introduction of minimally invasive liver surgery.

\section{Acknowledgements}

We would like to thank our collegues from the Dutch Liver Collaborative Group for the kind assistance and cooperation.

\section{Disclosure Statement}

The authors disclose no conflicts of interest.

\section{References}

1 Reddick EJ, Olsen DO: Laparoscopic laser cholecystectomy. A comparison with minilap cholecystectomy. Surg Endosc 1989;3: 131-133.

2 Dubois F, Berthelot G, Levard H: Laparoscopic cholecystectomy: historic perspective and personal experience. Surg Laparosc Endosc 1991; 1:52-57.

$\checkmark 3$ Dagher I, Proske JM, Carloni A, Richa H, et al: Laparoscopic liver resection: results for 70 patients. Surg Endosc 2007;21:619-624.

$\checkmark 4$ Descottes B, Glineur D, Lachachi F, et al: Laparoscopic liver resection of benign liver tumors. Surg Endosc 2003;17:23-30.

$\checkmark 5$ Farges O, Jagot P, Kirstetter P, Marty J, et al: Prospective assessment of the safety and benefit of laparoscopic liver resections. J Hepatobiliary Pancreat Surg 2002;9:242248.

6 Morino M, Morra I, Rosso E, Miglietta C, et al: Laparoscopic vs open hepatic resection: a comparative study. Surg Endosc 2003;17: 1914-1918.

$\checkmark 7$ Simillis C, Constantinides VA, Tekkis PP, et al: Laparoscopic versus open hepatic resections for benign and malignant neoplasms a meta-analysis. Surgery 2007;141:203-211.

$\checkmark 8$ Kaneko H: Laparoscopic hepatectomy: indications and outcomes. J Hepatobiliary Pancreat Surg 2005;12:438-443.

$\checkmark 9$ Cherqui D, Husson E, Hammoud R, Malassagne $\mathrm{B}$, et al: Laparoscopic liver resections: a feasibility study in 30 patients. Ann Surg 2000;232:753-762.
10 Buell JF, Thomas MJ, Doty TC, Gersin KS, et al: An initial experience and evolution of laparoscopic hepatic resectional surgery. Surgery 2004;136:804-811.

11 Chang S, Laurent A, Tayar C, Karoui M, Cherqui D: Laparoscopy as a routine approach for left lateral sectionectomy. $\mathrm{Br} J$ Surg 2007;94:58-63.

12 Gigot JF, Glineur D, Santiago Azagra J, Goergen $\mathrm{M}$, et al: Laparoscopic liver resection for malignant liver tumors: preliminary results of a multicenter European study. Ann Surg 2002;236:90-97.

-13 Buell JF, Cherqui D, Geller DA, O’Rourke N, et al: The international position on laparoscopic liver surgery: The Louisville Statement, 2008. Ann Surg 2009;250:825-830.

14 Nguyen KT, Gamblin TC, Geller DA: World review of laparoscopic liver resection-2,804 patients. Ann Surg 2009;250:831-841.

15 Reddy SK, Tsung A, Geller DA: Laparoscopic liver resection. World J Surg 2010, Epub ahead of print

16 Stoot JH, van Dam RM, Busch OR, van Hillegersberg $\mathrm{R}$, et al: The effect of a multimodal fast-track programme on outcomes in laparoscopic liver surgery: a multicentre pilot study. HPB (Oxford) 2009;11:140-144.

17 van Dam RM, Hendry PO, Coolsen MM, et al: Initial experience with a multimodal enhanced recovery programme in patients undergoing liver resection. Br J Surg 2008;95: 969-975.
18 Dindo D, Demartines N, Clavien PA: Classification of surgical complications: a new proposal with evaluation in a cohort of 6336 patients and results of a survey. Ann Surg 2004;240:205-213.

19 Cuesta MA, Meijer S, Paul MA, et al: Limited laparoscopic liver resection of benign tumors guided by laparoscopic ultrasonography: report of two cases. Surg Laparosc Endosc 1995;5:396-401.

20 Berends FJ, Meijer S, Prevoo W, et al: Technical considerations in laparoscopic liver surgery. Surg Endosc 2001;15:794-798.

21 van Keimpema L, Hockerstedt K: Treatment of polycystic liver disease. Br J Surg 2009;96: 1379-1380.

22 van Keimpema L, Ruurda JP, Ernst MF, van Geffen HJ, Drenth JP: Laparoscopic fenestration of liver cysts in polycystic liver disease results in a median volume reduction of 12.5\%. J Gastrointest Surg 2008;12:477-482.

23 Schipper HG, Kager PA: Diagnosis and treatment of hepatic echinococcosis: an overview. Scand J Gastroenterol Suppl 2004;241:50-55.

24 de Jong KP, Hesselink EJ, Laméris JS, Ottow RT, Terpstra OT: Partial liver resection (in Dutch). Ned Tijdschr Geneeskd 1989;133: 2381-2384.

25 de Jong KP, Blankensteijn JD, Hesselink EJ, Laméris JS, Terpstra OT: Partial hepatectomy for benign or malignant liver diseases; experience in 94 patients (in Dutch). Ned Tijdschr Geneeskd 1989;133:2385-2388. 
-26 van Ooijen B, Wiggers T, Meijer S, et al: Hepatic resections for colorectal metastases in The Netherlands. A multiinstitutional 10year study. Cancer 1992;70:28-34

-27 Cuesta MA, Meijer S, Borgstein PJ, Mulder LS, Sikkenk AC: Laparoscopic ultrasonography for hepatobiliary and pancreatic malignancy. Br J Surg 1993;80:1571-1574.

28 van Gulik T: Open versus laparoscopic resection for liver tumours. HPB (Oxford) 2009; 11:465-468.

-29 Miles WF, Paterson-Brown S, Garden OJ: Laparoscopic contact hepatic ultrasonography. Br J Surg 1992;79:419-420.

>30 Windsor JA, Garden OJ: Laparoscopic ultrasonography. Aust N Z J Surg 1993;63:1-2.

-31 Nieveen van Dijkum EJ, de Wit LT, van Delden OM, Kruyt PM, et al: Staging laparoscopy and laparoscopic ultrasonography in more than 400 patients with upper gastrointestinal carcinoma. J Am Coll Surg 1999; 189:459-465.

>32 Gouma DJ, de Wit LT, Nieveen van Dijkum E, Van Delden O, et al: Laparoscopic ultrasonography for staging of gastrointestinal malignancy. Scand J Gastroenterol Suppl 1996; 218:43-49.

-33 Cherqui D, Soubrane O, Husson E, Barshasz E, Vignaux O, et al: Laparoscopic living donor hepatectomy for liver transplantation in children. Lancet 2002;359:392-396.

-34 Giulianotti PC, Coratti A, Angelini M, Sbrana F, et al: Robotics in general surgery: personal experience in a large community hospital. Arch Surg 2003;138:777-784.

-35 Vibert E, Denet C, Gayet B: Major digestive surgery using a remote-controlled robot: the next revolution. Arch Surg 2003;138:10021006.
36 Cherqui D: Laparoscopic liver resection. Br J Surg 2003;90:644-646.

37 Shimada M, Hashizume M, Maehara S, Tsujita E, et al: Laparoscopic hepatectomy for hepatocellular carcinoma. Surg Endosc 2001;15:541-544.

38 Pulitano C, Aldrighetti L: The current role of laparoscopic liver resection for the treatment of liver tumors. Nat Clin Pract Gastroenterol Hepatol 2008;5:648-654.

>39 Vigano L, Tayar C, Laurent A, Cherqui D: Laparoscopic liver resection: a systematic review. J Hepatobiliary Pancreat Surg 2009;16: 410-421.

40 Polignano FM, Quyn AJ, de Figueiredo RS, Henderson NA, Kulli C, Tait IS: Laparoscopic versus open liver segmentectomy: prospective, case-matched, intention-to-treat analysis of clinical outcomes and cost effectiveness. Surg Endosc 2008;22:2564-2570.

41 Vanounou T, Steel JL, Nguyen KT, Tsung A et al: Comparing the clinical and economic impact of laparoscopic versus open liver resection. Ann Surg Oncol 2010;17:998-1009.

42 Nguyen KT, Gamblin TC, Geller DA: World review of laparoscopic liver resection - 2,804 patients. Ann Surg 2009;250:831-841.

43 Hashizume M, Shimada M, Sugimachi K: Laparoscopic hepatectomy: new approach for hepatocellular carcinoma. J Hepatobiliary Pancreat Surg 2000;7:270-275.

44 Johnstone PA, Rohde DC, Swartz SE, Fetter JE, Wexner SD: Port site recurrences after laparoscopic and thoracoscopic procedures in malignancy. J Clin Oncol 1996;14:19501956.

45 Gutt CN, Riemer V, Kim ZG, Erceg J, Lorenz M: Impact of laparoscopic surgery on experimental hepatic metastases. Br J Surg 2001; 88:371-375.

-46 Targarona EM, Martínez J, Nadal A, Balagué $\mathrm{C}$, et al: Cancer dissemination during laparoscopic surgery: tubes, gas, and cells. World J Surg 1998;22:55-60; discussion 60-61.
47 Laurent A, Cherqui D, Lesurtel M, Brunetti F, et al: Laparoscopic liver resection for subcapsular hepatocellular carcinoma complicating chronic liver disease. Arch Surg 2003; 138:763-769, discussion 769.

48 Mala T, Edwin B, Gladhaug I, Fosse E, et al: A comparative study of the short-term outcome following open and laparoscopic liver resection of colorectal metastases. Surg Endosc 2002; 16:1059-1063.

49 Cherqui D, Laurent A, Tayar C, Chang S, et al: Laparoscopic liver resection for peripheral hepatocellular carcinoma in patients with chronic liver disease: midterm results and perspectives. Ann Surg 2006;243:499506.

50 Teramoto K, Kawamura T, Takamatsu S, Noguchi $\mathrm{N}$, et al: Laparoscopic and thoracoscopic partial hepatectomy for hepatocellular carcinoma. World J Surg 2003;27:11311136.

51 Vibert E, Perniceni T, Levard H, Denet C, et al: Laparoscopic liver resection. Br J Surg 2006;93:67-72.

52 Mala T, Edwin B, Rosseland AR, Gladhaug I, et al: Laparoscopic liver resection: experience of 53 procedures at a single center. J Hepatobiliary Pancreat Surg 2005;12:298303.

53 Dulucq JL, Wintringer P, Stabilini C, Berticelli J, Mahajna A: Laparoscopic liver resections: a single center experience. Surg Endosc 2005;19:886-891.

54 Katkhouda N, Hurwitz M, Gugenheim J, Mavor E, et al: Laparoscopic management of benign solid and cystic lesions of the liver. Ann Surg 1999;229:460-466. 